\title{
A Common Structural Component for $\beta$-Subunit Mediated Modulation of Slow Inactivation in Different $\mathrm{K}_{\mathrm{v}}$ Channels
}

\author{
Nathalie Strutz-Seebohm ${ }^{a} \quad$ Ulrike Henrion ${ }^{a} \quad$ Nicole Schmitt ${ }^{b} \quad$ Eric Schulze-Bahr ${ }^{a}$ \\ Guiscard Seebohma \\ anstitute for Genetics of Heart Diseases (IfGH), Department of Cardiovascular Medicine, University \\ Hospital Münster, Münster, Germany; 'bepartment of Biomedical Sciences, Faculty of Health and \\ Medical Sciences, University of Copenhagen, Copenhagen N, Denmark
}

\section{Key Words}

Ion channel $\cdot$ Modulation $\cdot$ Gating $\cdot$ Conduction $\bullet \beta$-subunit

\begin{abstract}
Background/Aims: Potassium channels are tetrameric proteins providing potassium selective passage through lipid embedded proteinaceous pores with highest fidelity. The selectivity results from binding to discrete potassium binding sites and stabilization of a hydrated potassium ion in a central internal cavity. The four potassium binding sites, generated by the conserved TTXGYGD signature sequence are formed by the backbone carbonyls of the amino acids TXGYG. Residues $\mathrm{K}_{\mathrm{v}} 1.5-\mathrm{Val} 481, \mathrm{~K}_{\mathrm{v}} 4.3-$ Leu368 and $\mathrm{K}_{\mathrm{v}}$ 7.1-Ile313 represent the amino acids in the $X$ position of the respective channels. Methods: Here, we study the impact of these residues on ion selectivity, permeation and inactivation kinetics as well as the modulation by $\beta$-subunits using site-specific mutagenesis, electrophysiological analyses and molecular dynamics simulations. Results: We identify this position as key in modulation of slow inactivation by structurally dissimilar $\beta$-subunits in different $\mathrm{K}_{\mathrm{v}}$ channels. Conclusion: We propose a model in which structural changes accompanying activation and $\beta$-subunit modulation allosterically constrain the backbone carbonyl oxygen atoms via the side chain of the respective $\mathrm{X}$-residue in the signature sequence to reduce conductance during slow inactivation.
\end{abstract}

\section{Introduction}

Ion channels regulate the membrane potential of excitable cells. Voltage-gated potassium $\left(\mathrm{K}_{\mathrm{v}}\right)$ channels are composed of four $\alpha$-subunits, each containing an S5-S6 segment region encompassing the aqueous pore and a S1-S4 segment voltage sensor region. The selectivity filter is encoded by a highly conserved amino acid signature sequence TT $\underline{X} G Y G D$, where $X$ is a valine in about $80 \%$ of the $\mathrm{K}^{+}$channel sequences (Fig. 1a). Less common residues are Ile 
and Leu (Fig. 1a). The crystal structure of the bacterial KcsA channel revealed the molecular mechanisms of ion selectivity and high rates of ion conductance [1-4]. Each of the residues TXGYG provides carbonyl oxygen atoms from four identical subunits to line up in a narrow pore with four potential binding sites for dehydrated $\mathrm{K}^{+}$ions, two of which are normally occupied at any time [5] to allow for potassium flow and stability of the selectivity filter (Fig. 1b).

The KcsA channel conducts potassium whereby two to three ions are driven through the selectivity filter with increased residency times at specific ion binding sites (named S1-S4) within the selectivity filter [6]. The KcsA crystal structure showed two distinct conformations of the selectivity filter, and the equilibrium between these conformations is determined by the $\mathrm{K}^{+}$concentration. At high $\mathrm{K}^{+}$concentrations the selectivity filter adopts a structure compatible with ion conduction including hydrated/semi-hydrated $\mathrm{K}^{+}$in the central cavity and the outer mouth of the channel and two $\mathrm{K}^{+}$ions separated by a single $\mathrm{H}_{2} \mathrm{O}$ molecule in the selectivity filter. At low $\mathrm{K}^{+}$(in the low millimolar range), the filter loses one of its dehydrated $\mathrm{K}^{+}$ions and undergoes compensatory structural changes that render it non-conductive. These conformational changes are crucial to the operation of the selectivity filter in the cellular context, where the $\mathrm{K}^{+}$concentration varies in response to channel gating [4]. Homology modeling suggests a very similar scenario for $K_{v}$ channels like $K_{v} 7.1$ (Fig. 1b). This channel contains the signature sequence TTIGYGD (Fig. 1b).

$\mathrm{K}_{\mathrm{V}}$ channels undergo conformational changes leading to the defined open (conducting) and closed (non-conducting) gating states. In many channels there are additional nonconducting "inactivated" states, which follow the open states after prolonged activating physiological stimuli. Inactivation of $\mathrm{K}_{\mathrm{v}}$ channels can occur by P-type, fast $\mathrm{N}$-type or slow C-type mechanisms, with $\mathrm{N}$-type referring to the $\mathrm{N}$-terminus, $\mathrm{P}$-type referring to the pore domain and C-type to the C-terminus. These structural regions were proposed to play key roles in the different types of the gating mechanisms. It has been suggested that P-type inactivation involves a slight constriction of the narrow canal formed by the selectivity filter, causing a transient increase in the permeability of $\mathrm{Na}^{+}$relative to $\mathrm{K}^{+}$before a channel ceases to conduct [7]. Possibly, the transient $\mathrm{Na}^{+}$conduction of the channels represents the conformational changes of the selectivity filter, and thus modulation of $\mathrm{K}^{+}$-binding sites with differing affinities for $\mathrm{K}^{+}$during inactivation was proposed. C-type inactivation involves parts of the pore domain allosterically modulating the selectivity filter. The exact molecular mechanism of C-type inactivation has still to be resolved and may differ among the various channels. Inactivation in channels like $\mathrm{K}_{\mathrm{v}} 1.5$ and $\mathrm{K}_{\mathrm{v}} 4.3$ are considered as classical and atypical $\mathrm{C}$-type inactivation, respectively. $\mathrm{N}$-type inactivation involves an $\mathrm{N}$-terminal peptide which is thought to block ion passage by binding to the central cavity [8]. A similar ball-peptide allowing for channel blockage is present in $\mathrm{K}_{\mathrm{v}} \beta$-subunits [7]. Likewise, a $\mathrm{K}_{\mathrm{v}} \beta 1.3-\mathrm{N}$-terminal loop induces an $\mathrm{N}$-type inactivation in $\mathrm{K}_{\mathrm{v}} 1.5$ by a pore blocking mechanism [9]. Alternatively, an N-type inactivation-prevention (NIP) domain present in the $\mathrm{K}_{\mathrm{v}} 1.6$ amino terminus might abolish N-type inactivation [10]. Mutant residues located in the extracellular P-loop of $\mathrm{K}_{\mathrm{v}}$ channels have been shown to affect slow C-type inactivation [11], and removal of external potassium ions results in increased slow C-type inactivation, and destabilized conduction states by the collapse of the selectivity filter [12-16]. On the other hand, increase of the external $\mathrm{K}^{+}$-concentration accelerates recovery from inactivation by voltage-dependent binding to the outer $\mathrm{K}^{+}$-binding site [17]. In summary, $\mathrm{K}^{+}$channels need external potassium ions to have $\mathrm{K}^{+}$-occupied selectivity filters and reduced inactivation. Thus, slow C-type inactivation represents a stabilized P-type inactivated state of the channel [18]. Slow C-type channel inactivation is proposed to result from concerted larger scale rearrangements of the four $\alpha$-subunits [19-21]. During slow inactivation in $\mathrm{K}_{\mathrm{v}} 1.5$ gating charge is immobilized [22, 23]. The slow inactivation in $K_{v}$ channels including $K_{v} 1 . x$ and $K_{v} 4 . x$ channels is modulated by structurally distinct $\beta$-subunits, $\mathrm{K}_{\mathrm{v}} \beta 1 \mathrm{~s}$ and KChIPs respectively, which both may transfer structural constraints on the selectivity filter via the transmembrane segments S5 and S6 $[24,25]$. KChIPs bind to the N-terminal tetramerization domain (T1-domain) of $\mathrm{K}_{\mathrm{v}} 4$ channels [26]. However, it has not been determined which key residue (if any single one) is 
Fig. 1. Alignment of the selectivity filter sequences of $\mathrm{K}_{\mathrm{v}}$ channels, homology model of $\mathrm{K}_{\mathrm{v}} 7.1$ and mode of modulation of $\mathrm{K}_{\mathrm{v}}$ channels by structurally different $\beta$ subunits. $a$, sequence alignment of several potassium channel selectivity filters and pore helices. The investigated residue in the selectivity filter consensus sequence (gray) is boxed. $b$, two adjacent subunits of a homology model of $\mathrm{hK}_{\mathrm{v}} 7.1$ are shown. Part of one subunit is shown in surface rendered presentation (green). The selectivity filter residues TIGYG in the adjacent subunit are shown in space fill and colored in CPK coloring $\left(\mathrm{K}^{+}=\right.$yellow, $\mathrm{O}=$ red, $\mathrm{N}=$ blue $\mathrm{C}=$ cyan $)$. Carbons of residue Ile313 is colored gray. The four putative potassium binding sites within the selectivity filter are depicted by potassium ions K1-4. K1 binds to the potassium binding site $S 1$, $\mathrm{K} 2$ to $S 2, \mathrm{~K} 3$ to $S 3$ and K4 to $S 4$. The backbone of the subunit in front is shown in the upper figures but was removed from the lower figures for clarity. The side chain of Ile313 is positioned in a crevice of the adjacent subunit, providing a structural link between two subunits and the selectivity filter $\left(\mathrm{K}^{+}\right.$ binding sites $\mathrm{K} 2$ and $\mathrm{K} 3$ ). Note that most often only two potassium ions (high $\mathrm{K}^{+}$concentration) or one (low $\mathrm{K}^{+}$concentration) reside in the selectivity filter at a given time point. $c$. The channels $\mathrm{K}_{\mathrm{v}} 1.5, \mathrm{~K}_{\mathrm{v}} 4.3$ and $\mathrm{K}_{\mathrm{v}} 7.1$ (gray/striped) are depicted together with their $\beta$-subunits $\mathrm{K}_{\mathrm{v}} \beta 1.3$, KChIP2.2 and KCNE1 (dark gray), respectively. The hypothetical main structural constraints on the selectivity filter by the respective $\beta$-subunit are indicated by arrows, whereas red arrows indicate facilitation and green arrows indicate reduction of slow inactivation.

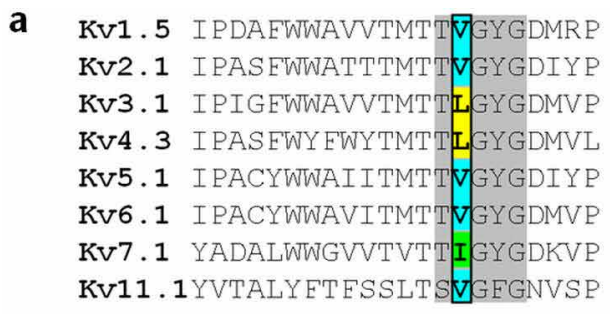

a Kv1.5 IPDAFWWAVVTMTTVGGYGMRP KV2.1 IPASEWWATTTMTTVGYGDIYP KV3.1 IPIGEWWAVVTMTTL GYGDMVP KV4.3 IPASEWYEWYTMTTLGYGDMVL KV5. 1 IPACYWWAIITMTTVGYGDIYP KV6.1 IPACYWWAVITMTTVGYGDMVP KV7.1 YADALWWGVVTVTTI GYGDKVP KV11.1YVTALYETESSLTSUGEGNVSP

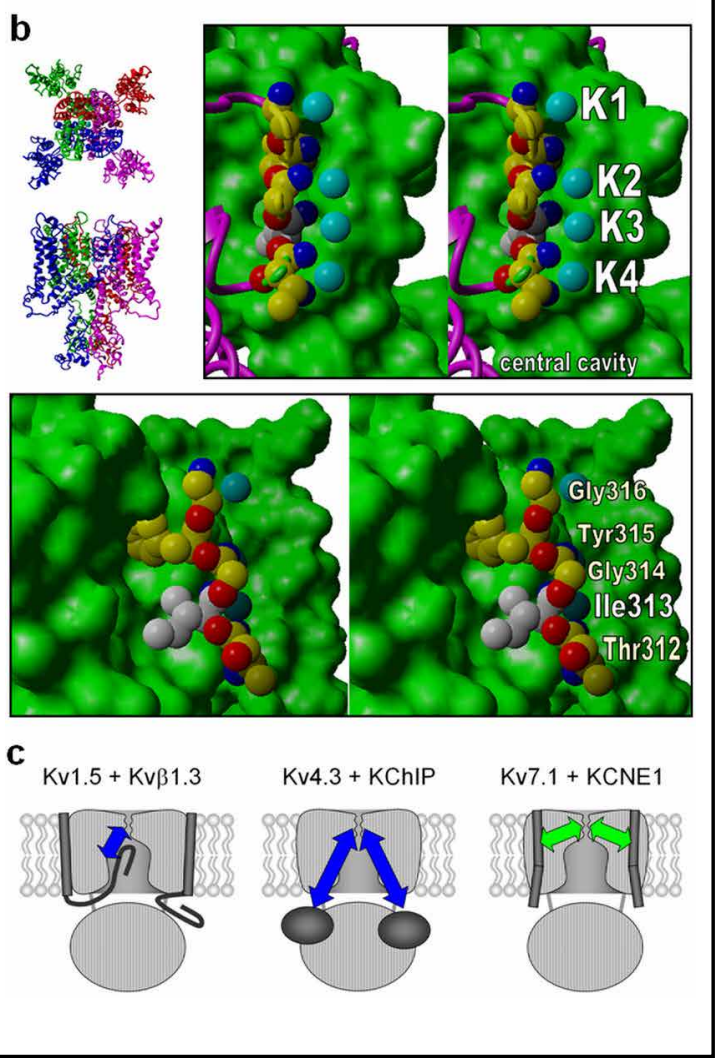

mediating the communication between the selectivity filter and outer channel structures. On the contrary, inactivation in homomeric $\mathrm{K}_{\mathrm{V}} 7.1$ channels does not display the characteristic features of $\mathrm{N}$ - or slow $\mathrm{C}$-type inactivation. The weak voltage sensitivity of $\mathrm{K}_{\mathrm{v}} 7.1$ inactivation, the lack of high $\mathrm{K}^{+}$sensitivity together with delayed onset of inactivation and the lack of an $\mathrm{N}$-terminal ball structure within $\mathrm{K}_{\mathrm{v}} 7.1$ differ from $\mathrm{N}$-type inactivation $[27,28]$. $\mathrm{K}_{\mathrm{v}} 7.1$ open states might flicker at high rates resulting in the macroscopic incomplete inactivation [29, 30]. Structurally, an interaction of the lower pore helix and the transmembrane segments $\mathrm{S} 5$ and $\mathrm{S} 6$ is important for $\mathrm{K}_{\mathrm{V}} 7.1$ inactivation [31-33]. Recently, a similar S6-pore helix interaction was proposed to be crucial for inactivation in $\mathrm{K}_{\mathrm{v}} 1.2$ and KcsA [34].

In contrast to the action of $\mathrm{Kv} \beta 1$ subunits on $\mathrm{Kv} 1$ channels inactivation of $\mathrm{K}_{\mathrm{v}} 7.1$ is not facilitated but abolished by coassembly with KCNE1 $\beta$-subunits $[27,35]$. This suggests that interacting domains of these two proteins might also influence the inactivation process itself. The different mechanisms of $\beta$-subunit mediated modulation of inactivation are depicted in the cartoon in Fig. 1c. Despite all these differences there are similarities: Slow inactivation involves the respective selectivity filter which must be involved in the modulation of inactivation by structurally very different $\beta$-subunits. A candidate residue which could be involved in these processes by sensing inter-subunit conformational changes as a result of gating and $\beta$-subunit interaction is the $X$ residue in the center of the selectivity filter. 
Here, we use a site-directed mutagenesis approach to delineate the relative importance of a residue in the selectivity filter of $\mathrm{K}_{\mathrm{v}} 1.5, \mathrm{~K}_{\mathrm{v}} 4.3$, and $\mathrm{K}_{\mathrm{v}} 7.1$ either alone or co-expressed with their $\beta$-subunits $\mathrm{K}_{\mathrm{v}} \beta 1.3$, KChIP2.2 or KCNE1, respectively. Mutation of the central residue $(\mathrm{X})$ in the position TTXGYGD in $\mathrm{K}_{\mathrm{v}} 1.5$ affected only the level of permeation, whereas the same mutations in the $\mathrm{K}_{\mathrm{v}} 4.3$ and $\mathrm{K}_{\mathrm{v}} 7.1$ selectivity filters had functional effects on current amplitudes, voltage-dependent gating and, in the case of $\mathrm{K}_{\mathrm{v}} 7.1$, altered selectivity. Surprisingly, we show that the chemical nature of the residue in the X-position has strong effects on modulation of inactivation by the $\beta$-subunits $\mathrm{K}_{\mathrm{v}} \beta 1.3$ and KChIP2.2 on $\mathrm{K}_{\mathrm{v}} 1.5$ and $\mathrm{K}_{\mathrm{v}} 4.3$, whereby specific properties become evident. Interestingly, marked differences among WT $\mathrm{K}_{\mathrm{v}} 7.1$ channels and functionally altered mutants are overridden by coexpression with KCNE1. The data presented here identify a crucial residue in the selectivity filter for modulation of inactivation and macroscopic conduction by structurally distinct $\beta$-subunits.

\section{Material and Methods}

\section{Molecular Biology}

The molecular biological procedures were the same as previously described [31]. Human $\mathrm{K}_{\mathrm{v}} 1.5, \mathrm{~K}_{\mathrm{v}} 4.3$ and $\mathrm{K}_{\mathrm{v}} 7.1$ cDNA were subcloned into the oocyte expression vector pSGEM. The cDNA were mutated at positions Val481 ( $\mathrm{K}_{\mathrm{v}}$ 1.5), Leu368 $\left(\mathrm{K}_{\mathrm{v}} 4.3\right)$ and Ile313 $\left(\mathrm{K}_{\mathrm{v}} 7.1\right)$ by site-directed mutagenesis using PCR with cloned Pfu-polymerase. All constructs were confirmed by automated DNA sequencing.

\section{Oocyte expression}

Xenopus laevis frogs were tricaine (0.17\%)-anesthetized and ovarian lobes were removed. Female Xenopus laevis were killed after surgical removal of ovarian lobes following protocols approved by the animal welfare office of the Ruhr-University Bochum in accordance with the guidelines of the European Community (86/609/EEC). This applies specifically for this study. All efforts were made to minimize animal suffering. The ovarian lobes were cut into small pieces and were enzymatically treated for $1.5-2 \mathrm{~h}$ with collagenase ( $1 \mathrm{mg} / \mathrm{ml}$, Worthington, type II) at room temperature in ND96-Ca ${ }^{2+}$-free solution (in mM: 96 $\mathrm{NaCl}, 2 \mathrm{KCl}, 1 \mathrm{MgCl}_{2}, 5$ HEPES (pH 7.6)). Stage V oocytes were collected and injected with $~ 50 \mathrm{nl}$ of cRNA. The oocytes were incubated at $17-18^{\circ} \mathrm{C}$ for 3-4 days. Oocytes were injected with 2 ng $\mathrm{K}_{\mathrm{v}} 1.5 \mathrm{cRNA}$ with or without $0.5 \mathrm{ng} \mathrm{K} / \mathrm{v} 1.3 \mathrm{cRNA}$ or with $1 \mathrm{ng}$ of $\mathrm{K}_{\mathrm{v}} 4.3 \mathrm{cRNA}$ with or without $1 \mathrm{ng}$ of KChIP2.2 $c$ RNA or with $5 \mathrm{ng}$ of $\mathrm{K}_{\mathrm{v}} 7.1 \mathrm{cRNA}$ with or without $1 \mathrm{ng}$ of KCNE1 cRNA. Oocytes were stored at $17-18^{\circ} \mathrm{C}$ in ND96-storage solution (in mM: $96 \mathrm{NaCl}, 4 \mathrm{KCl}, 1.8 \mathrm{MgC1}_{2}, 0.1 \mathrm{CaC1}_{2}, 5$ HEPES (N-[2-hydroxyethyl]piperazine- $\mathrm{N}$ '-[2-ethanesulfonic acid]), gentamycin (50 mg/l); $\mathrm{pH} 7.6)$.

\section{Western Blot}

Western blot of $\mathrm{K}_{\mathrm{v}} 7.1$ plasma membrane proteins: Surface proteins were tagged with Sulfo-NHS-LCBiotin and subsequently isolated by NeutrAvidin-mediated precipitation of biotinylated proteins.

\section{Electrophysiology}

Whole cell currents in Xenopus oocytes were recorded with standard two-electrode-voltage-clamp techniques with a Turbo TEC10-CX amplifier (NPI) at room temperature $\left(22-24^{\circ} \mathrm{C}\right)$ [31]. Data were acquired with Clampex (pCLAMP 8.0, Axon Instruments) and analyzed with ClampFit (pCLAMP 8.0, Axon Instruments) and Origin 6.0 (Microcal). Whole cell currents were recorded in ND96-recording solution (in mM: $96 \mathrm{NaCl}, 4 \mathrm{KCl}, 1.8 \mathrm{MgC1}_{2}, 0.1 \mathrm{CaC1}_{2}, 5$ HEPES; pH 7.6).

Reversal potential $\mathrm{E}_{\text {rev }}$ of an ion $\mathrm{X}$ was collected and the shift of $\mathrm{E}_{\mathrm{rev}}$ compared to $\mathrm{E}_{\text {rev }}$ in high $\mathrm{K}^{+}$were determined and the ratio of the permeability of the monovalent test cation to $\mathrm{K}^{+}$was then calculated from the derivation of the Goldmann-Hodkin-Katz equation [36]:

$\mathrm{E}_{\mathrm{rev}}=(\mathrm{RT} / \mathrm{F}) \ln \left\{\left(\mathrm{P}_{\mathrm{X}}\left[\mathrm{X}_{\mathrm{o}}\right]\right) /\left(\mathrm{P}_{\mathrm{K}}\left[\mathrm{K}_{\mathrm{o}}^{+}\right]\right)\right\}$.

$\left[\mathrm{X}_{0}\right]$ and $\left[\mathrm{K}_{0}^{+}\right]$are the ionic activities of $\mathrm{X}^{+}$and $\mathrm{K}^{+}$in the external solution and $\mathrm{P}_{\mathrm{X}}$ and $\mathrm{P}_{\mathrm{K}}$ are the permeabilities of $\mathrm{I}_{\mathrm{K}}$ to the test cation $\mathrm{X}^{+}$and $\mathrm{K}^{+}$.

The recovery from inactivation in $\mathrm{K}_{\mathrm{v}} 1.5 / 4.3$ channels: The channels were C-type inactivated by a $2 \mathrm{~s}$ conditional pulse to $+50 \mathrm{mV}$, followed by recovering interpulses of variable length (50 ms increments) to 
$-100 \mathrm{mV}$ and then the activating fraction of channels was measured at $+50 \mathrm{mV}$. The current amplitude of the second depolarizing pulse was measured and the current at the end of the conditioning prepulse was subtracted to analyze only the recovering fraction of channels.

Tail current analysis at a potential of $-120 \mathrm{mV}$ was used to assess the voltage dependence of $\mathrm{K}_{\mathrm{v}} 7.1$ channel activation and inactivation [37, 38]. Tail currents were fitted to a bi-exponential equation of the form:

$I(t)=a_{s} \exp \left(-t / \tau_{s}\right)-a_{f} \exp \left(-t / \tau_{f}\right)+a_{0}$,

with a fast time constant $\tau$ and a slow time constant $\tau_{\mathrm{S}}$, and their respective amplitudes, $\mathrm{a}_{\mathrm{f}}$ and $\mathrm{a}_{\mathrm{s}^{\prime}}$, and an offset current, $a_{0}$. The relative fast component, $a$, represents the magnitude of inactivation [10].

The amplitude of the faster time constant ${ }^{\mathrm{f}}$ of this double-exponential relaxation was of variable magnitude for $\mathrm{K}_{\mathrm{v}} 7.1-\mathrm{I} 313 \mathrm{~V}$ and for $\mathrm{K}_{\mathrm{v}} 7.1 \mathrm{WT}$ relative to the slow deactivating component. Accordingly, the fraction of inactivated channels was given by $\mathrm{a}_{\mathrm{s}} / \mathrm{a}_{\mathrm{f}},[37]$.

Molecular modeling

A consensus homology model was generated. Several individual modeling steps using YASARA Structure version 10.1. were required.

\section{Results}

Slow inactivation in $\mathrm{K}_{\mathrm{v}} 1.5, \mathrm{~K}_{\mathrm{v}} 4.3$ and $\mathrm{K}_{\mathrm{v}} 7.1$ may originate from different mechanisms. Further, the channels are modulated by structurally very different $\beta$-subunits. Classical slow C-type inactivation in $\mathrm{K}_{\mathrm{v}} 1$ channels is affected by mutations in the selectivity filter and the outer vestibule and represents a stabilized P-type inactivation $[11,18]$. To test whether mutations in the selectivity filter affect $\mathrm{K}_{\mathrm{v}} 1.5$ channel C-type inactivation in the same way as in $\mathrm{K}_{\mathrm{v}} 4.3$ and $\mathrm{K}_{\mathrm{v}} 7.1$, we replaced $\mathrm{K}_{\mathrm{v}} 1.5$ Val481 by Ala, Leu and Ile in the $\mathrm{X}$ position in the TTX GYG signature sequence of $\mathrm{K}_{\mathrm{v}} 1.5$ resulting in mutants $\mathrm{K}_{\mathrm{v}} 1.5(\mathrm{VA}), \mathrm{K}_{\mathrm{v}} 1.5(\mathrm{VL})$ and $\mathrm{K}_{\mathrm{v}} 1.5(\mathrm{VI})$. We expressed these channels in oocytes and analyzed the effects on current amplitude and kinetics. All channels were functional but showed differences in current amplitudes. WT- $\mathrm{K}_{\mathrm{v}} 1.5, \mathrm{~K}_{\mathrm{v}} 1.5(\mathrm{VV})$ and $\mathrm{K}_{\mathrm{v}} 1.5(\mathrm{VL})$ had virtually identical current amplitudes, whereas $\mathrm{K}_{\mathrm{v}} 1.5(\mathrm{VA})$ and especially $\mathrm{K}_{\mathrm{v}} 1.5(\mathrm{VI})$ showed reduced current magnitudes compared to WTchannels (Fig. 2a-b). Pore mutations in $\mathrm{K}_{\mathrm{v}} 1.5$ had only little effects on the rates of activation, inactivation and recovery from inactivation (Fig. 2c-e).

$\mathrm{K}_{\mathrm{v}} \beta 1.3$ contains an inactivation ball peptide that can bind to the central cavity of $\mathrm{K}_{\mathrm{v}} 1 . \mathrm{x}$ channels to facilitate both $\mathrm{N}$-type and C-type inactivation [39]. Upon co-expression of $\mathrm{K}_{\mathrm{v}} 1.5$ channels with $\mathrm{K}_{\mathrm{v}} \beta 1.3$ we found that the rates of inactivation were largely dependent on the specific residue in the $X$ position of the selectivity filter sequence: The mutations decreased the rates of inactivation in the rank order (amino acid in the $X$ position): $\mathrm{L}>\mathrm{I}>\mathrm{A}>\mathrm{V}$ (= WT). Thus, this central selectivity filter residue determines the rates of $K_{v} \beta 1.3$ - facilitated $\mathrm{K}_{\mathrm{v}} 1.5$ inactivation. However, we did not find any marked alterations in the recovery from inactivation in the $\mathrm{K}_{\mathrm{v}} 1.5$ mutants co-expressed with $\mathrm{K}_{\mathrm{v}} \beta 1.3$ compared to WT channels (Fig. 2c-d).

To determine the potential importance of the amino acid $\mathrm{X}$ in the selectivity filter of $\mathrm{K}_{\mathrm{v}} 4.3$ channels, we mutated this X-residue from Leu to Ala, Val, and Ile resulting in mutants $\mathrm{K}_{\mathrm{v}} 4.3(\mathrm{LA}), \mathrm{K}_{\mathrm{v}} 4.3(\mathrm{LV})$, and $\mathrm{K}_{\mathrm{v}} 4.3(\mathrm{LI})$. All mutant $\mathrm{K}_{\mathrm{v}} 4.3$ channels were functional but the mutants passed smaller currents than WT channels (Fig. $3 \mathrm{a}-\mathrm{b}$ ). The rate of activation of $\mathrm{K}_{\mathrm{v}} 4.3(\mathrm{LI})$ was strongly decreased by KChIP2.2 at all activating voltages tested (Fig. 3e), whereas a decrease in rate of activation was seen for $\mathrm{K}_{\mathrm{v}} 4.3(\mathrm{LL})$ and $\mathrm{K}_{\mathrm{v}} 4.3(\mathrm{LV})$ especially at lower activating voltages (Fig. 3e). The rate of activation and onset of inactivation was strongly decreased in $\mathrm{K}_{\mathrm{v}} 4.3$ (LA) channels. Also, the recovery from inactivation was modulated by the mutant channels to different degrees compared to WT- $\mathrm{K}_{\mathrm{v}} 4.3$ channels (Fig. 3c-e). WT and mutant $\mathrm{K}_{\mathrm{v}} 4.3$ channels had similar current amplitudes when co-expressed with KChIP2.2 (Fig. 3a). Interestingly, the inactivation rate was slowed by co-expression with KChIP2.2 for all $\mathrm{K}_{\mathrm{v}} 4.3$ channels except for $\mathrm{K}_{\mathrm{v}} 4.3(\mathrm{LA})$, where no decrease in the rate of inactivation was detected. 
Fig. 2. Effects of $K_{v} \beta 1.3$ on WT and selectivity filter mutant $\mathrm{K}_{\mathrm{v}} 1.5$ channels. $a, \mathrm{~K}_{\mathrm{v}} 1.5$ channels were mutated at residue Val481. WT $\mathrm{K}_{\mathrm{v}} 1.5$ and $\mathrm{K}_{\mathrm{v}} 1.5$ mutants were expressed in Xenopus oocytes. Currents were elicited from a holding potential of $-80 \mathrm{mV}$ by $2 \mathrm{~s}$ pulses applied in $10-\mathrm{mV}$ increments to potentials ranging from $-80 \mathrm{mV}$ to $+80 \mathrm{mV}$. $b$, mean peak current magnitudes \pm SEM was measured at the end of the depolarizing pulses $(\mathrm{n}=8-15) . c$,

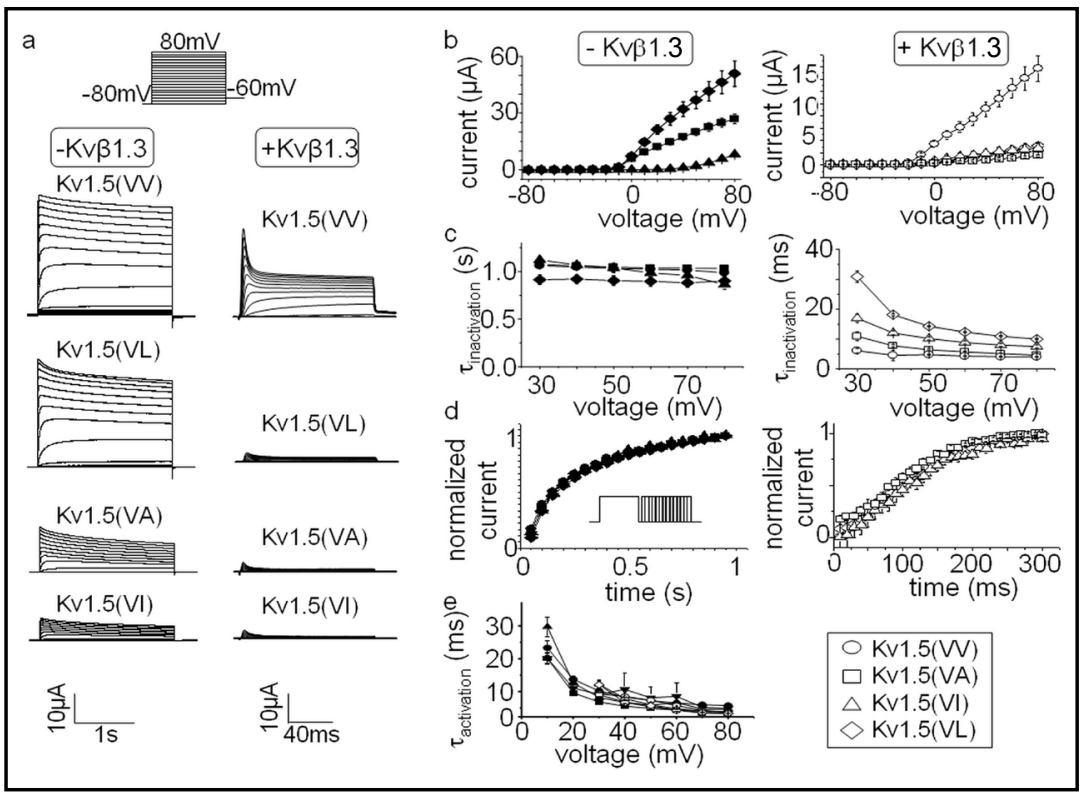

the decaying phase after activation was fitted to a single exponential function, and the time constants of inactivation $\tau_{\text {inactivation }}$ were plotted vs. the potential of the depolarizing pulse. Here, we use relatively small amount of $\mathrm{K}_{\mathrm{v}} \beta 1.3 \mathrm{cRNA}$ leading relatively slow recovery from inactivation. $d$, channels were partially inactivated, recovered by a hyperpolarising pulse, and subsequently activated again. The fraction of channels recovered from inactivation was analyzed as described in methods. The fraction of recovered channels was normalized to the values after $1 \mathrm{~s}$ interpulses and plotted vs. the interpulse lengths. The data are represented as mean $\pm \mathrm{SEM}$.

Fig. 3. Effects of KChIP2.2 on WT and selectivity filter mutant $\mathrm{K}_{\mathrm{v}} 4.3$ channels. $a, \mathrm{~K}_{\mathrm{v}} 4.3$ channels were mutated at residue Val481, the residue homologous to $\mathrm{K}_{\mathrm{v}} 7.1$ Ile313. WT $\mathrm{K}_{\mathrm{v}} 4.3$ and $\mathrm{K}_{\mathrm{v}} 4.3$ mutants were expressed in Xenopus oocytes. Currents were elicited from a holding potential of $-80 \mathrm{mV}$ by $2 \mathrm{~s}$ pulses applied in 20-mV increments to potentials ranging from $-80 \mathrm{mV}$ to $+60 \mathrm{mV} . b$, the peak current magnitude was measured at the end of the depolarizing

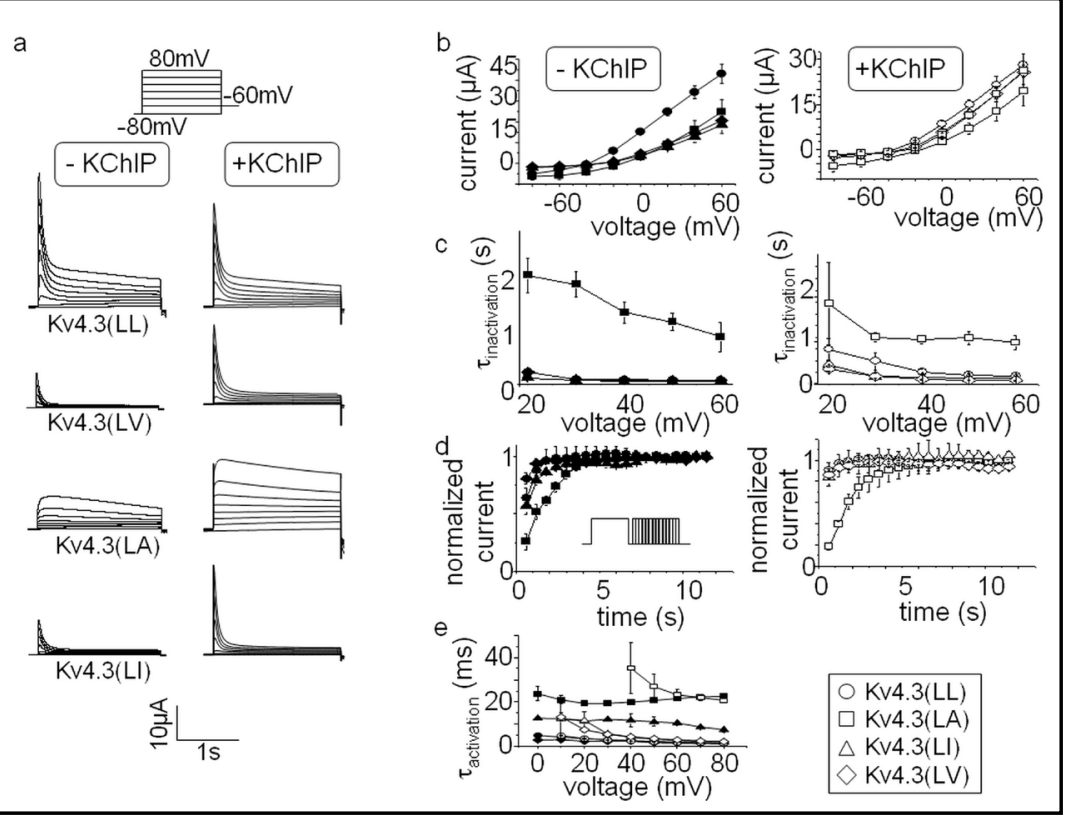
pulses and the mean currents \pm SEM are shown $(n=8-15) . c$, the decaying phase after activation was fit to a single exponential function and the time constants of inactivation $\tau_{\text {inactivation }}$ were plotted vs. the potential of the depolarizing pulse. $d$, using a similar double pulse protocol as in Fig. 2 the fraction of channels recovered from inactivation was analyzed. The fraction of recovered channels was normalized to the values after $1 \mathrm{~s}$ interpulses and plotted vs. the interpulse lengths. The data are presented as mean \pm SEM. 
Fig. 4. Mutations of residues in the selectivity filter of $\mathrm{K}_{\mathrm{v}} 7.1$ channels and modulation by KCNE1. $a, \mathrm{~K}_{\mathrm{v}} 7.1$ currents recorded from Xenopus oocytes. Currents were elicited from a holding potential of $-80 \mathrm{mV}$ with pulses applied in $20-\mathrm{mV}$ increments to potentials ranging from -120 $\mathrm{mV}$ to $+60 \mathrm{mV}$. $b, \mathrm{WT}-\mathrm{K}_{\mathrm{v}} 7.1$ and mutant currents were measured at the end of $3 \mathrm{~s}$ pulses and the mean amplitudes were plotted vs. the voltage. $c$, Tail currents were fit to two exponentials and the slow deactivating component was extrapolated to the beginning of the hyperpolarizing pulse. The amplitude at this point was measured and the mean amplitudes were plotted vs. the voltage. $d$, Currents were elicited from a holding potential of -80 $\mathrm{mV}$ with pulses to $40 \mathrm{mV}$ and then deactivated by pulses from $-140 \mathrm{mV}$ to $-80 \mathrm{mV}$ applied in $20-\mathrm{mV}$ increments. Traces were scaled to the same size to facilitate comparison. $e$, Tail currents were a

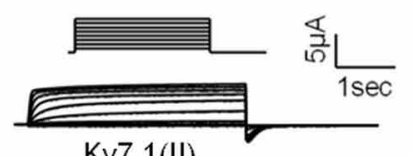

Kv7.1(II)
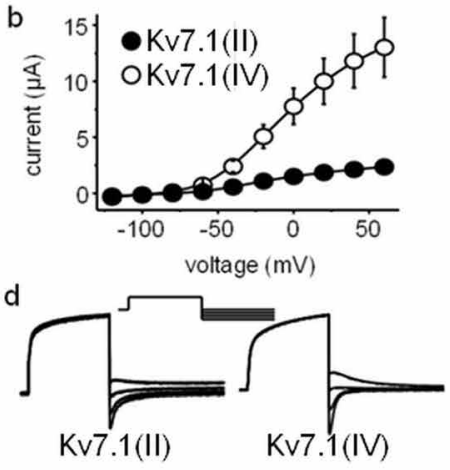

f
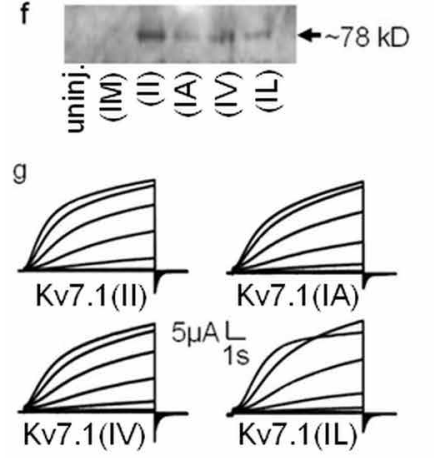

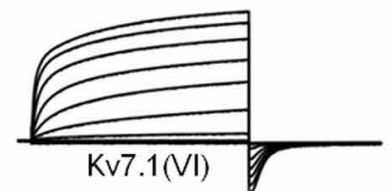

C
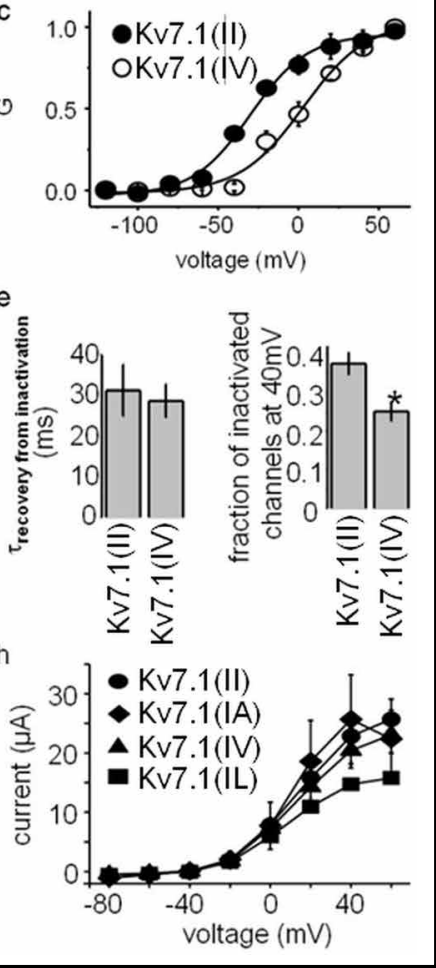

analyzed to determine the time constants of recovery from inactivation and the fraction of inactivated channels as described in methods. $f$, Panel shows a Western blot of $\mathrm{K}_{\mathrm{v}} 7.1$ membrane protein enriched by biotinylation. Samples including controls from uninjected oocytes were separated on a SDS gel, Westernblotted and probed with a polyclonal $\mathrm{K}_{\mathrm{v}} 7.1$ antibody directed against a peptide mapping at the $\mathrm{C}$-terminus of $\mathrm{K}_{\mathrm{v}}$ 7.1. $\mathrm{K}_{\mathrm{v}} 7.1$ protein has an apparent molecular weight of $\sim 78 \mathrm{kDa} . g, \mathrm{~K}_{\mathrm{v}} 7.1$ was co-expressed with KCNE1 in Xenopus oocytes. $\mathrm{I}_{\mathrm{Ks}}$ was elicited from a holding potential of $-80 \mathrm{mV}$ by $7 \mathrm{~s}$ pulses applied in $20-\mathrm{mV}$ increments to potentials ranging from $-120 \mathrm{mV}$ to $+60 \mathrm{mV}$. $h$, The peak current magnitude was measured at the end of the depolarizing pulses and the mean currents \pm SEM are shown in $b(\mathrm{n}=8-9)$.

Indeed, KChIP2.2 accelerated inactivation of $\mathrm{K}_{\mathrm{v}} 4.3$ (LA) at a few potentials (Fig. 3c). Further, $\mathrm{K}_{\mathrm{v}} 4.3(\mathrm{LA})$ activation time constants and recovery from inactivation failed to be robustly modulated by KChIP2.2 (Fig. 3d). Thus, mutant $\mathrm{K}_{\mathrm{v}} 4.3(\mathrm{LA})$ escapes kinetic modulation by KChIP2.2.

Mutation of $\mathrm{X}$ residue $\mathrm{I} 313$ in $\mathrm{K}_{\mathrm{v}} 7.1$ to Val ( $\mathrm{K}_{\mathrm{v}} 7.1$ (IV)), the most common amino acid at this position of potassium-selective channels, resulted in a dramatic increase in current amplitude (around 5-6-fold at $+50 \mathrm{mV}$ ) (Fig. 4a-b). This effect was accompanied by a rightward shift of the activation curve (Fig. 4c). The deactivation was not significantly altered but as a result of the shifted voltage-dependence of activation, the fraction of inactivated channels was decreased (Fig. 4d-e). Mutations of I313 in $\mathrm{K}_{\mathrm{v}} 7.1$ to Ala or Leu (K $\mathrm{K}_{\mathrm{v}} 7.1$ (IA), $\mathrm{K}_{\mathrm{v}} 7.1$ (IL)) resulted in non-functional channels. Biotinylation experiments followed by western blotting showed that $\mathrm{K}_{\mathrm{v}} 7.1$ (IA) and $\mathrm{K}_{\mathrm{v}} 7.1(\mathrm{IL})$ reached the membrane. WT- $\mathrm{K}_{\mathrm{v}} 7.1$ and mutant channels were co-expressed with the $\beta$-subunit KCNE1. WT- and mutant $\mathrm{K}_{\mathrm{v}} 7.1 / \mathrm{KCNE} 1$ expressed functionally to produce the slow delayed rectifier $\mathrm{K}^{+}$current, $\mathrm{I}_{\mathrm{Ks}}$, with increased current magnitude, a slowed rate of activation, no apparent inactivation and an increased single channel conductance $[27,28,35,40]$ compared to $\mathrm{K}_{\mathrm{V}} 7.1$ expressed alone. $\mathrm{I}_{\mathrm{Ks}}$ was recorded 


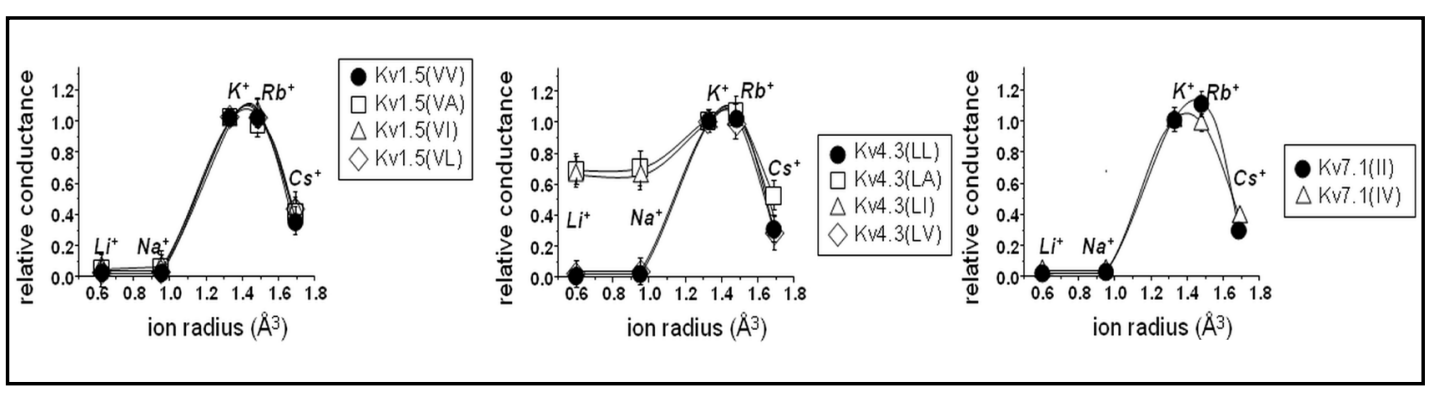

Fig. 5. Relative wild-type and mutant channel ion selectivity. Channels were expressed in Xenopus oocytes and the reversal potentials in solutions containing only one monovalent ion at $100 \mathrm{mM}$ were determined. Using the Goldmann-Hodkin-Katz equation the relative ion selectivity was determined as described in the Material and Methods section.

by 7-s pulses to potentials ranging from -80 to $+60 \mathrm{mV}$ and the current traces showed similar kinetics for WT and mutant channels. $\mathrm{K}_{\mathrm{v}} 7.1(\mathrm{IL}) / \mathrm{KCNE} 1$ channels showed a weak rectification at $+60 \mathrm{mV}$ (Fig. $4 \mathrm{~g}$ ). Thus, co-expression with KCNE1 rescues the functional impairment observed in the mutants in which the X residue in the selectivity filter was altered (Fig. 4h).

Of note, genetic variation at $\mathrm{K}_{\mathrm{v}} 7.1$ position $\mathrm{I} 313$ has previously been linked to the Long QT-syndrome [41]. Expression of the respective mutant I313M ( $\mathrm{K}_{\mathrm{v}} 7.1(\mathrm{IM})$ ) led to nonfunctional channels. Assessing surface expression of $\mathrm{K}_{\mathrm{v}} 7.1(\mathrm{IM})$ by western blot analysis showed that the mutant channels were absent in plasma membranes (Fig. 4f).

Slow inactivation involves the selectivity filter which determines the $\mathrm{K}^{+}$selectivity. To test for changes of the selectivity as a result of altered selectivity filter structure, we assayed relative ion selectivities. We examined all channels for their relative selectivity compared to the respective $\mathrm{K}^{+}$selectivity. The exchange of monovalent cations affected the reversal potential to different degrees in the particular mutant $\mathrm{K}_{\mathrm{v}}$ channels. No changes in ion selectivity as a result of mutations were found for $K_{v} 1.5$ channels (Fig. 5). However, we observed that the reversal potentials for the mutant channels $\mathrm{K}_{\mathrm{v}} 4.3(\mathrm{LA})$ and $\mathrm{K}_{\mathrm{v}} 4.3(\mathrm{LI})$ shifted to the right, suggesting reduced $\mathrm{K}^{+}$selectivity. The mutations $\mathrm{K}_{\mathrm{v}} 4.3(\mathrm{LA})$ and $\mathrm{K}_{\mathrm{v}} 4.3(\mathrm{LI})$ weakened the strict selectivity of channels for $\mathrm{Rb}^{+}$and $\mathrm{K}^{+}$over $\mathrm{Li}^{+}, \mathrm{Na}^{+}$and $\mathrm{Cs}^{+}$reducing the selectivity towards the smaller ions $\mathrm{Li}^{+}$and $\mathrm{Na}^{+}$compared to WT- $\mathrm{K}_{\mathrm{v}} 4.3$ channels (Fig. 5). The rank orders for relative selectivities were: $\mathrm{Rb}^{+}=\mathrm{K}^{+}>\mathrm{Cs}^{+}>\mathrm{Na}^{+}=\mathrm{Li}^{+}$. The only exceptions were $\mathrm{K}_{\mathrm{v}} 4.3(\mathrm{LA})$ and $\mathrm{K}_{\mathrm{v}} 4.3(\mathrm{LI})$ with a rank order of: $\mathrm{Rb}^{+}=\mathrm{K}^{+}>\mathrm{Cs}^{+} \sim \mathrm{Na}^{+} \sim \mathrm{Li}^{+}$. WT- $\mathrm{K}_{\mathrm{v}} 7.1$ channels conduct $\mathrm{Rb}^{+}$to a higher degree as $\mathrm{K}^{+}$. This effect was blunted in the $\mathrm{K}_{\mathrm{v}} 7.1$ (IV). Taken together, the selectivity of ion channels is differently affected by the chemical nature of the central $\mathrm{X}$-residue in the selectivity filter.

To gain further insight into the nature of these effects, we performed homology modeling and subsequent molecular dynamics simulations on WT and mutant $\mathrm{K}_{\mathrm{v}}$ channels. We analyzed the dynamics of potassium ion coordination during simulations and determined average positions of the chain of $\mathrm{K}^{+}$ions (Fig. 6). These simulations indicate that $\mathrm{K}_{\mathrm{v}} 1.5$ exhibits minute changes in the positions of $\mathrm{K}^{+}$ions, whereas the positions of $\mathrm{K}^{+}$ions in the selectivity filters of $\mathrm{K}_{\mathrm{v}} 4.3$ and $\mathrm{K}_{\mathrm{v}} 7.1$ were markedly different in mutant channels compared to WT channels as suggested by the Root Mean Square Deviation (RMSD) calculations (Fig. 6). Interestingly, the patterns of $\mathrm{K}^{+}$ions suggest the most evenly spaced positions for all three WT channels compared to respective X-residue mutant $\left(\mathrm{K}_{\mathrm{v}} 1.5: \mathrm{K} 1-\mathrm{K} 2=5.2 \AA\right.$, $\mathrm{K} 2-\mathrm{K} 3=4.4$ $\AA ; \mathrm{K}_{\mathrm{v}} 4.3: \mathrm{K} 1-\mathrm{K} 2=6.8 \AA, \mathrm{K} 2-\mathrm{K} 3=3.8 \AA, \mathrm{K} 3-\mathrm{K} 4=7.8 \AA$; $\mathrm{K}_{\mathrm{v}} 7.1: \mathrm{K} 1-\mathrm{K} 2=5.6 \AA, \mathrm{K} 2-\mathrm{K} 3=3.7 \AA$, $\mathrm{K} 3-\mathrm{K} 4=9.6 \AA$ ). Interestingly, the distances among respective potassium ions in $\mathrm{K}_{\mathrm{v}} 4.3 \mathrm{WT}$ and $\mathrm{K}_{\mathrm{v}} 7.1 \mathrm{WT}$ are very similar. The relatively evenly spaced $\mathrm{K}^{+}$even patters are altered to different degrees by the respective mutations as depicted in Fig. 6 . To gain insights into the dynamics of potassium coordination, we calculated Root Mean $\underline{\text { Square }}$ Fluctuations (RMSFs) around the mean position. Marked differences in RMSFs are suggested for X-residue mutants (Fig. 6), possibly as a result of reduced affinity of the respective potassium ion to its binding site. Therefore, the X-residue may affect binding of potassium ion to respective binding sites. 


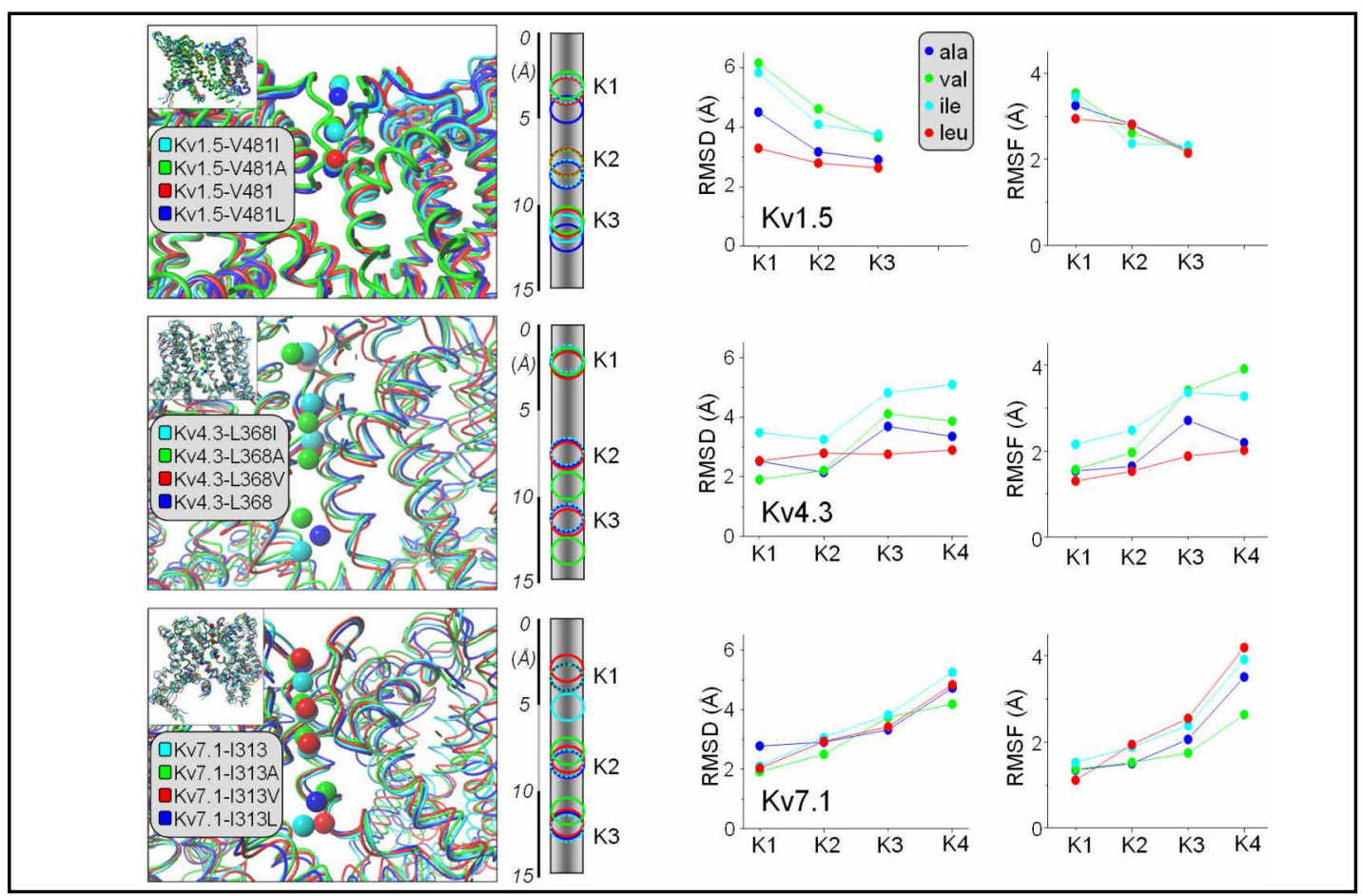

Fig. 6. Simulated occupancies of WT and mutant potassium channel selectivity filters. $a, \mathrm{~K}_{\mathrm{v}} 1.5, \mathrm{~K}_{\mathrm{v}} 4.3$ and $\mathrm{K}_{\mathrm{v}} 7.1$ channels and their respective mutants were modeled based on the solved and refined crystal structure of $\mathrm{K}_{\mathrm{v}} 1.2$ (pdb: $\left.3 \mathrm{LUT}\right)^{55}$ with good results. The selectivity filters were modeled fully occupied by $\mathrm{K}^{+}$. The channels were incorporated in membranes and all atoms mobile molecular dynamics simulations were performed. In a first 5 ns equilibration simulation, $\mathrm{K}_{\mathrm{v}}$ models were allowed to reach a stable. Mutagenesis of the X-residue and further 1 ns simulations were performed starting with the equilibrated WT models. The average structures of the WT and mutant channel models including their potassium ions are colored as indicated in the small boxes and are shown superimposed. The structures of the models were cut on the level of the potassium ion in the selectivity filters. The potassium ions are shown without cutting. The relative position of the ions in the selectivity filter was analyzed and is shown as symbols right to 3D-models. The circles indicate the average position of the potassium ions (color coded like in the models beneath). Root mean square fluctuations (RMSD) from the start of $1 \mathrm{~ns}$ simulations and Root mean square fluctuations (RMSF) during $1 \mathrm{~ns}$ simulations were calculated for the bound potassium ions in the selectivity filters (K1, $\mathrm{K} 2$ and K3). In the case of $\mathrm{K}_{\mathrm{v}} 1.5$, the central cavity potassium ion (K4) left the central cavity during the $5 \mathrm{~ns}$ equilibration simulation and the potassium ion coordinated in the central cavity could only be calculated for $\mathrm{K}_{\mathrm{v}} 4.3$ and $\mathrm{K}_{\mathrm{v}} 7.1$.

\section{Discussion}

All potassium channels have a consensus sequence $T(S) T(S) \underline{X} G Y(F)$ G (with the sequence TTVGYG being the most common one) characterizing the selectivity filter. In the X position only the three amino acids Val, Ile and Leu - all with hydrophobic side chains - are found (Fig. 1). $\mathrm{K}_{\mathrm{v}} 1.5$ harbors the most common (about $80 \%$ of $\mathrm{K}^{+}$channels) Val, $\mathrm{K}_{\mathrm{v}} 4.3$ a Leu and Kv7.1 an Ile at the X-site. As the selectivity filter is involved in slow P/C-type inactivation we aimed to test for the relevance of the precise amino acid at the $\mathrm{X}$ position for slow $\mathrm{K}_{\mathrm{v}}$ inactivation. Here, we mutated this residue within the selectivity filters of $\mathrm{K}_{\mathrm{v}} 1.5, \mathrm{~K}_{\mathrm{v}} 4.3$, and $\mathrm{K}_{\mathrm{v}} 7.1$ channels. We find that the X-residue determines current amplitudes in all $\mathrm{K}_{\mathrm{v}}$ channels (Fig. 2-4). Differences of the mutants in macroscopic current amplitudes were most dramatic in $\mathrm{K}_{\mathrm{v}}$ 7.1, ranging from loss-of-function (IA and IL) to strong gain-of-function (IV) (Fig. 4a-b). These large differences are not explained by different plasma membrane expression (Fig. 
4f). Possibly, the X-residue is important in determining the fractions of active channels and "sleepers" (channels present in the plasma membrane but not activated upon membrane potential depolarization, possibly due to closed state inactivation), as has been shown for sodium channels [42].

The crystallographic distribution of potassium ions in the selectivity filter was found to be altered with the potassium concentration. In high potassium, the potassium binding sites $S 1-S 4$ are equally occupied by $\mathrm{K}^{+}$, but in low potassium, especially the central binding sites $S 2$ and $S 3$, are not or weakly occupied as suggested by KcsA crystal structures [2]. $\mathrm{Rb}^{+}$, an ion slightly larger in size than potassium, shows a different crystallographic distribution in the selectivity filter and is conducted to a lower extent by KcsA because of imbalanced affinities of precise cation binding sites [2]. The $X$ residue of each $K_{v}$ subunit provides a backbone carbonyl group which is involved in formation of the central potassium binding sites $S 2$ and $S 3$ (Fig. 1). The side chain of the respective residue projects to the adjacent subunit and is involved in the formation of the interface between two subunits (Fig. 1). Comparing the KcsA structures in high vs. low $\mathrm{K}^{+}$the side chain of Val76, the residue in the $\mathrm{X}$ position, shows marked reorientations [2]. Restricting these reorientations by different side chains like Ala/Ile in $\mathrm{K}_{\mathrm{v}} 1.5$ or Ala in $\mathrm{K}_{\mathrm{v}} 4.3$ or Ala/Leu in $\mathrm{K}_{\mathrm{v}} 7.1$ might distort and/or reduce flexibility of the backbone carbonyls leading to modified $\mathrm{K}^{+}$affinity and imbalanced $\mathrm{K}^{+}$residency in the selectivity filter $\mathrm{K}^{+}$coordination sites. Simulations of molecular dynamics on KcsA suggested that intrinsic electrostatic properties of the carbonyls and their flexibility are indispensable for high potassium flux and selectivity $[3,43]$. Here, we simulate the potassium coordination. The simulations suggest that specific mutations alter the average positions in selectivity filters and stabilities/flexibilities of coordinated potassium ions (Fig. 6). These results indicate that the coordination of potassium ions in the selectivity filter is highly determined by the physicochemical nature of the X-residue. Marked differences in RMSFs were computed in X-residue mutants (Fig. 6). It can be expected that increased flexibility may result of reduced affinity of the respective potassium ion to its binding site. Therefore, the X-residue may be a determinant of binding of potassium ion to respective binding sites. As conduction is the result of subsequent binding of potassium ion to precise binding sites differences in affinity at potassium binding sites may result in an energetic barrier leading to substantially reduced conduction. The X-reside may thus be a key residue to tune the conduction rate of potassium ions.

In contrast to mutations in $\mathrm{K}_{\mathrm{v}} 4.3$ and $\mathrm{K}_{\mathrm{v}} 7.1$, inactivation rates in $\mathrm{K}_{\mathrm{v}} 1.5$ were not affected by mutations of the Val481 to Ala, Ile, and Leu. This indicates that classical slow C-type inactivation involves different residues than $\mathrm{K}_{\mathrm{v}}$ 4.3-type and $\mathrm{K}_{\mathrm{v}}$ 7.1-type inactivation. Indeed, pore closure at an extracellular potassium binding site, probably involving potassium binding sites $S O$ and/or $S 1$, was suggested for classical slow Shaker C-type inactivation but not for $\mathrm{K}_{\mathrm{v}} 4.3$ or $\mathrm{K}_{\mathrm{v}} 7.1$ [12-16].

In this study we find that the $\mathrm{X}$ residue in $\mathrm{K}_{\mathrm{v}} 1.5$ and $\mathrm{K}_{\mathrm{v}} 4.3$ channels can modulate the effects of structurally very distinct $\beta$-subunits on macroscopic inactivation kinetics (Fig. 2 , $3)$. Both, $\mathrm{K}_{\mathrm{v}} \beta 1.3$ and KChIP2.2 may affect the relative subunit-subunit interactions, which in turn may constrain the selectivity filter via the side chains of the $\mathrm{X}$ residue. In other words, the $X$ residue side chain may sense the relative orientation of adjacent $\alpha$ subunits and carry constraints forward to the central $\mathrm{K}^{+}$binding sites $S 2 / S 3$.

I313V-K $7.1\left(\mathrm{~K}_{\mathrm{v}} 7.1(\mathrm{IV})\right)$ has a decreased relative rubidium-conductance compared to WT- $\mathrm{K}_{\mathrm{v}} 7.1$ but increased whole cell currents (data not shown). These findings might suggest that analogous to the findings for the KcsA mutant T75C these mutants change the energetically balanced selectivity filter configurations $S 1 / S 3$ vs. $S 2 / S 4$. In $\mathrm{K}_{\mathrm{v}} 7.1$, the mutation of I313V could increase whole cell $\mathrm{K}^{+}$currents and $\mathrm{K}^{+}$selectivity indicating that WT- $\mathrm{K}_{\mathrm{v}} 7.1$ channels might not have a balanced $S 1 / S 3$ to $S 2 / S 4$ occupancy.

High $\mathrm{Rb}^{+}$favors occupancy of the $S 1 / S 3$ and $S 1 / S 4$ positions, whereas high $\mathrm{K}^{+}$almost equally occupies $S 1 / S 3$ and $S 2 / S 4$ as shown in KcsA structures [44]. In contrast to KcsA and most $\mathrm{K}_{\mathrm{v}}$ channels homomeric $\mathrm{K}_{\mathrm{v}} 7.1$ channels have increased $\mathrm{Rb}^{+}$conductance compared to $\mathrm{K}^{+}[2,38]$. We showed a tight coupling of $\mathrm{Rb}^{+}$conductance and inactivation in $\mathrm{K}_{\mathrm{v}} 7.1$ channels 
[30], indicating that inactivation may be a result from a $\mathrm{Rb}^{+} / \mathrm{K}^{+}$-modulated fast flicker present in $\mathrm{K}_{\mathrm{v}} 7.1$ channels $[29,45,46]$. The larger $\mathrm{Rb}^{+}$conductance compared to $\mathrm{K}^{+}$can be interpreted in the way that the $\mathrm{K}_{\mathrm{v}} 7.1$ selectivity filter has binding sites for permeating $\mathrm{K}^{+}$ which are energetically imbalanced (and thus not optimized for highest $\mathrm{K}^{+}$conduction) and that this imbalance can be partially compensated for by a slightly larger $\mathrm{Rb}^{+}$ion. Recently, we suggested a pinching/squeezing of the $\mathrm{K}_{\mathrm{v}} 7.1$ pore associated with a slow inactivation found in mutant channels, a process not counteracted by high $\mathrm{K}^{+}$concentrations, suggesting that, unlike in P-type inactivation in $\mathrm{K}_{\mathrm{v}} 7.1$ channels, other structures like the adjacent $\alpha$-subunit or the outer vestibule must be involved $[29,45,46]$. This macroscopic inactivation, which is only seen in current traces upon depolarization in specific $\mathrm{K}_{\mathrm{v}} 7.1$ mutants, is prominent in interaction sites of S5-S6 and the pore helix [32]. It can be expected that even small changes of the S5-S6 assembly might influence the selectivity filter. On the other hand, the occupancy of the selectivity filter influences the activation gate. The latter is underlined by the slowing of recovery from inactivation and delay of deactivation in high $\mathrm{Rb}^{+}$compared to high $\mathrm{K}^{+}$in WT- $\mathrm{K}_{\mathrm{v}} 7.1$ channels [29]. The activation gate at the PAG-motif is opened by outward deflection of the lower S6 helices, as suggested for Shakers PVP-motif [46], whereas the activation in $\mathrm{K}_{\mathrm{v}} 7.1$ channels might further be coupled to a small rotation of the S6 segment, as suggested for the channel EXP-2 [46, 47], and a rotated conformation of S6 seems to be stabilized by binding of the $\mathrm{K}_{\mathrm{v}} 7.1$ gating modifying activator R-L3 [48].

The accessory $\beta$-subunit KCNE1 slows activation kinetics, right-shifts conductancevoltage relationship, inhibits inactivation, equalizes $\mathrm{K}^{+}$and $\mathrm{Rb}^{+}$permeation, and slightly increases $\mathrm{Cs}^{+}$permeation $[13,27,35,37,49]$. Co-expression of KCNE1 with $\mathrm{K}_{\mathrm{v}} 7.1$ channels I313A/V/L results in currents which are kinetically and in size almost similar to WT- $\mathrm{K}_{\mathrm{v}} 7.1 /$ KCNE1 channel currents (Fig. 4). Based on the tail current reversal potentials ( 75-85 $\mathrm{mV}$ ), WT and mutant channels reflect normal $\mathrm{K}^{+}$over $\mathrm{Na}^{+}$selectivity. KCNE1 is therefore stabilizing/restoring a potassium selective high conductance state. Interestingly, in absence of KCNE1, $\mathrm{K}_{\mathrm{v}} 7.1$ - I313V right-shifts the GV-curve, decreases the relative $\mathrm{Rb}^{+}$permeation, facilitates $\mathrm{Cs}^{+}$permeation, increases macroscopic conductance, and reduces inactivation, thus partially mimicking the action of KCNE1 on $\mathrm{K}_{\mathrm{v}} 7.1$ (Fig. 4) [35]. It seems plausible that KCNE1 binds to $\mathrm{K}_{\mathrm{v}} 7.1$ S4-S6-segments [48-50], therewith stabilizing a particular, possibly rotated, conformation $[5,47,51]$, in which constraints are transferred via interactions of the S5, S6, and the pore helix [30-32] and Ile313 (Fig. 1d) at the subunit-subunit interface to the selectivity filter to allow for the selectivity filter to adopt a high conduction state (Fig. 1d). Thus, the WT- $\mathrm{K}_{\mathrm{v}} 7.1$ channel is in a low-conductance selectivity filter state, and KCNE1 may allosterically tune the selectivity filter in order to adopt a high-conductance selectivity filter conformation via the $\mathrm{X}$ residue.

In summary, we present data suggesting the importance of $X$ residues for selectivity, conduction and sensitivity towards modulation by $\beta$-subunits. Whereas effects of mutations in the X-positions in the different channels were variable, the mutant and WT channels suggest a common site for modulation of slow inactivation in $K_{v}$ channels. Supposedly, structural constraints imposed on the $\mathrm{K}_{\mathrm{v}}$ channels by the different $\beta$-subunits are allosterically transferred to the selectivity filter, affecting the central two potassium binding sites.

\section{Acknowledgments}

We thank Dr. Daniel Tapken and Prof. Dr. Raphael Stoll for comments on the manuscript.

\section{References}

1 Doyle DA, Morais Cabral J, Pfuetzner RA, Kuo A, Gulbis JM, Cohen SL, Chait BT, MacKinnon R: The structure of the potassium channel: Molecular basis of $\mathrm{K}^{+}$conduction and selectivity. Science 1998;280:69-77. 


\section{Cellular Physiology $\quad$ Cell Physiol Biochem 2013;31:968-980 and Biochemistry

-2 Morais-Cabral JH, Zhou Y, MacKinnon R: Energetic optimization of ion conduction rate by the $\mathrm{K}^{+}$selectivity filter. Nature 2001;414:37-42.

3 Noskov SY, Berneche S, Roux B: Control of ion selectivity in potassium channels by electrostatic and dynamic properties of carbonyl ligands. Nature 2004;431:830-834.

-4 Zhou Y, Morais-Cabral JH, Kaufman A, MacKinnon R: Chemistry of ion coordination and hydration revealed by a $\mathrm{K}^{+}$channel-fab complex at 2.0 a resolution. Nature 2001;414:43-48.

-5 Zhou Y, MacKinnon R: Ion binding affinity in the cavity of the kcsa potassium channel. Biochemistry 2004;43:4978-4982.

Berneche S, Roux B: Energetics of ion conduction through the $\mathrm{K}^{+}$channel. Nature 2001;414:73-77.

Kiss L, Korn SJ: Modulation of c-type inactivation by $\mathrm{K}^{+}$at the potassium channel selectivity filter. Biophys J 1998;74:1840-1849.

8 Zhou M, Morais-Cabral JH, Mann S, MacKinnon R: Potassium channel receptor site for the inactivation gate and quaternary amine inhibitors. Nature 2001;411:657-661.

-9 Decher N, Gonzalez T, Streit AK, Sachse FB, Renigunta V, Soom M, Heinemann SH, Daut J, Sanguinetti MC: Structural determinants of kvbeta1.3-induced channel inactivation: A hairpin modulated by pip2. Embo J 2008;27:3164-3174.

10 Roeper J, Sewing S, Zhang Y, Sommer T, Wanner SG, Pongs O: Nip domain prevents n-type inactivation in voltage-gated potassium channels. Nature 1998;391:390-393.

11 Smith PL, Baukrowitz T, Yellen G: The inward rectification mechanism of the herg cardiac potassium channel. Nature 1996;379:833-836.

$\checkmark 12$ Choi KL, Aldrich RW, Yellen G: Tetraethylammonium blockade distinguishes two inactivation mechanisms in voltage-activated $\mathrm{K}^{+}$channels. Proc Natl Acad Sci U S A 1991;88:5092-5095.

13 Eghbali M, Olcese R, Zarei MM, Toro L, Stefani E: External pore collapse as an inactivation mechanism for Kv4.3 K+ channels. J Membr Biol 2002;188:73-86.

14 Grissmer S, Cahalan M: Tea prevents inactivation while blocking open $\mathrm{K}^{+}$channels in human $\mathrm{t}$ lymphocytes. Biophys J 1989;55:203-206.

-15 Lopez-Barneo J, Hoshi T, Heinemann SH, Aldrich RW: Effects of external cations and mutations in the pore region on c-type inactivation of shaker potassium channels. Receptors Channels 1993;1:61-71.

16 Pardo LA, Heinemann SH, Terlau H, Ludewig U, Lorra C, Pongs O, Stuhmer W: Extracellular K ${ }^{+}$specifically modulates a rat brain $\mathrm{K}^{+}$channel. Proc Natl Acad Sci U S A 1992;89:2466-2470.

17 Levy DI, Deutsch C: A voltage-dependent role for $\mathrm{K}^{+}$in recovery from c-type inactivation. Biophys J 1996;71:3157-3166.

18 Loots E, Isacoff EY: Protein rearrangements underlying slow inactivation of the shaker $\mathrm{K}^{+}$channel. J Gen Physiol 1998;112:377-389.

19 MacKinnon R, Aldrich RW, Lee AW: Functional stoichiometry of shaker potassium channel inactivation. Science 1993;262:757-759.

-20 Ogielska EM, Zagotta WN, Hoshi T, Heinemann SH, Haab J, Aldrich RW: Cooperative subunit interactions in c-type inactivation of k channels. Biophys J 1995;69:2449-2457.

-21 Panyi G, Sheng Z, Deutsch C: C-type inactivation of a voltage-gated $\mathrm{K}^{+}$channel occurs by a cooperative mechanism. Biophys J 1995;69:896-903.

22 Wang Z, Fedida D: Gating charge immobilization caused by the transition between inactivated states in the Kv1.5 channel. Biophys J 2001;81:2614-2627.

23 Wang Z, Fedida D: Uncoupling of gating charge movement and closure of the ion pore during recovery from inactivation in the Kv1.5 channel. J Gen Physiol 2002;120:249-260.

24 Wittka R, Stocker M, Boheim G, Pongs O: Molecular basis for different rates of recovery from inactivation in the shaker potassium channel family. FEBS Lett 1991;286:193-200.

25 Jerng HH, Shahidullah M, Covarrubias M: Inactivation gating of Kv4 potassium channels: Molecular interactions involving the inner vestibule of the pore. J Gen Physiol 1999;113:641-660.

26 Pioletti M, Findeisen F, Hura GL, Minor DL Jr: Three-dimensional structure of the Kchip1-Kv4.3 t1 complex reveals a cross-shaped octamer. Nat Struct Mol Biol 2006;13:987-995.

-27 Sanguinetti MC, Curran ME, Zou A, Shen J, Spector PS, Atkinson DL, Keating MT: Coassembly of K(v)lqt1 and mink (isk) proteins to form cardiac i(ks) potassium channel. Nature 1996;384:80-83.

-28 Sesti F, Goldstein SA: Single-channel characteristics of wild-type iks channels and channels formed with two mink mutants that cause long qt syndrome. J Gen Physiol 1998;112:651-663. 
29 Pusch M, Bertorello L, Conti F: Gating and flickery block differentially affected by rubidium in homomeric Kcnq1 and heteromeric Kcnq1/Kcne1 potassium channels. Biophys J 2000;78:211-226.

30 Seebohm G, Sanguinetti MC, Pusch M: Tight coupling of rubidium conductance and inactivation in human Kcnq1 potassium channels. J Physiol 2003;552:369-378.

31 Seebohm G, Scherer CR, Busch AE, Lerche C: Identification of specific pore residues mediating Kcnq1 inactivation. A novel mechanism for long qt syndrome. J Biol Chem 2001;276:13600-13605.

-32 Seebohm G, Westenskow P, Lang F, Sanguinetti MC: Mutation of colocalized residues of the pore helix and transmembrane segments $\mathrm{s} 5$ and s 6 disrupt deactivation and modify inactivation of kcnq $1 \mathrm{~K}^{+}$channels. J Physiol 2005;563:359-368.

33 Shalaby FY, Levesque PC, Yang WP, Little WA, Conder ML, Jenkins-West T, Blanar MA: Dominant-negative Kvlqt1 mutations underlie the lqt1 form of long qt syndrome. Circulation 1997;96:1733-1736.

-34 Cuello LG, Jogini V, Cortes DM, Pan AC, Gagnon DG, Dalmas O, Cordero-Morales JF, Chakrapani S, Roux B, Perozo E: Structural basis for the coupling between activation and inactivation gates in $\mathrm{K}^{+}$channels. Nature 2010;466:272-275.

-35 Barhanin J, Lesage F, Guillemare E, Fink M, Lazdunski M, Romey G: K(v)lqt1 and lsk (mink) proteins associate to form the i(ks) cardiac potassium current. Nature 1996;384:78-80.

36 Hille B: The permeability of the sodium channel to organic cations in myelinated nerve. J Gen Physiol 1971;58:599-619.

-37 Pusch M, Magrassi R, Wollnik B, Conti F: Activation and inactivation of homomeric Kvlqt1 potassium channels. Biophys J 1998;75:785-792.

-38 Tristani-Firouzi M, Sanguinetti MC: Voltage-dependent inactivation of the human $\mathrm{K}^{+}$channel Kvlqt1 is eliminated by association with minimal $\mathrm{K}^{+}$channel (mink) subunits. J Physiol 1998;510:37-45.

-39 Wang Z, Kiehn J, Yang Q, Brown AM, Wible BA: Comparison of binding and block produced by alternatively spliced kvbeta1 subunits. J Biol Chem 1996;271:28311-28317.

40 Yang Y, Sigworth FJ: Single-channel properties of iks potassium channels. J Gen Physiol 1998;112:665-678.

41 Tanaka T, Nagai R, Tomoike H, Takata S, Yano K, Yabuta K, Haneda N, Nakano O, Shibata A, Sawayama T, Kasai H, Yazaki Y, Nakamura Y: Four novel Kvlqt1 and four novel herg mutations in familial long-qt syndrome. Circulation 1997;95:565-567.

42 Greeff NG, Kuhn FJ: Variable ratio of permeability to gating charge of rbiia sodium channels and sodium influx in xenopus oocytes. Biophys J 2000;79:2434-2453.

43 Jensen MO, Borhani DW, Lindorff-Larsen K, Maragakis P, Jogini V, Eastwood MP, Dror RO, Shaw DE: Principles of conduction and hydrophobic gating in $\mathrm{K}^{+}$channels. Proc Natl Acad Sci U S A 2010;107:58335838.

44 Zhou M, MacKinnon R: A mutant $\mathrm{kcsa} \mathrm{K}^{+}$channel with altered conduction properties and selectivity filter ion distribution. J Mol Biol 2004;338:839-846.

-45 Gibor G, Yakubovich D, Rosenhouse-Dantsker A, Peretz A, Schottelndreier H, Seebohm G, Dascal N, Logothetis DE, Paas Y, Attali B: An inactivation gate in the selectivity filter of Kcnq1 potassium channels. Biophys J 2007;93:4159-4172.

46 Peretz A, Sheinin A, Yue C, Degani-Katzav N, Gibor G, Nachman R, Gopin A, Tam E, Shabat D, Yaari Y, Attali B: Pre- and postsynaptic activation of $\mathrm{m}$-channels by a novel opener dampens neuronal firing and transmitter release. J Neurophysiol 2007;97:283-295.

47 Perozo E, Cortes DM, Cuello LG: Structural rearrangements underlying $\mathrm{K}^{+}$-channel activation gating. Science 1999;285:73-78.

48 Seebohm G, Pusch M, Chen J, Sanguinetti MC: Pharmacological activation of normal and arrhythmiaassociated mutant kcnq1 potassium channels. Circ Res 2003;93:941-947.

49 Pusch M, Ferrera L, Friedrich T: Two open states and rate-limiting gating steps revealed by intracellular $\mathrm{Na}^{+}$ block of human Kcnq1 and Kcnq1/Kcne1 K+ channels. J Physiol 2001;533:135-143.

50 Melman YF, Um SY, Krumerman A, Kagan A, McDonald TV: Kcne1 binds to the Kcnq1 pore to regulate potassium channel activity. Neuron 2004;42:927-937.

51 Espinosa F, Fleischhauer R, McMahon A, Joho RH: Dynamic interaction of s5 and s6 during voltagecontrolled gating in a potassium channel. J Gen Physiol 2001;118:157-170. 